\title{
Physiological controls on seawater uptake and calcification in the benthic foraminifer Ammonia tepida
}

\author{
L. J. de Nooijer ${ }^{1}$, G. Langer ${ }^{1,2}$, G. Nehrke ${ }^{1}$, and J. Bijma ${ }^{1}$ \\ ${ }^{1}$ Alfred Wegener Institute for Polar- and Marine Research (AWI), Am Handelshafen 12, 27570 Bremerhaven, Germany \\ ${ }^{2}$ Institute of Environmental Science and Technology, Universitat Autònoma de Barcelona (UAB), 08193 Bellaterra, Spain
}

Received: 7 July 2009 - Published in Biogeosciences Discuss.: 16 July 2009

Revised: 17 November 2009 - Accepted: 19 November 2009 - Published: 27 November 2009

\begin{abstract}
To analyze the relation between seawater uptake and calcification, we incubated juveniles of the benthic foraminifer Ammonia tepida with various fluorescent probes and visualised them afterwards with confocal laser scanning microscopy. Vesicle membranes, $\mathrm{Ca}$ ions and vacuole fluids were followed with various tracers and showed for the first time that endocytosis of seawater is part of the calcification process in Ammonia tepida. Data on the intracellular $\mathrm{Ca}$ ion cycling allowed for calculating a preliminary cellular $\mathrm{Ca}$ budget during foraminiferal calcification. This showed that the free calcium involved in the production of a new chamber cannot be sufficient and suggests that foraminifera may precipitate their calcite from an amorphous precursor.
\end{abstract}

\section{Introduction}

Fossil foraminiferal calcite carries imprints from past oceanic conditions since incorporation of many trace elements and stable isotopes is correlated to specific environmental conditions. For example, foraminiferal $\mathrm{Mg} / \mathrm{Ca}$ ratios and $\delta^{18} \mathrm{O}$ can be adopted to reconstruct past marine temperatures (e.g. Lear et al., 2000). Calibrations for these relationships are based on culturing (e.g. Nürnberg et al., 1996) and field studies (e.g. Elderfield and Ganssen, 2000), that have shown that the $\mathrm{Mg} / \mathrm{Ca}$ ratio is partly determined by seawater salinity (e.g. Nürnberg et al., 1996) and inorganic carbon chemistry (e.g. Elderfield et al., 2006). Data presented in these studies have shown large differences to data from inorganic precipitation experiments (e.g. Mucci, 1986; Morse and Bender, 1990) and therefore imply that foraminiferal cal-

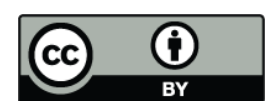

Correspondence to: L. J. de Nooijer (lnooijer@awi.de) cite formation is biologically controlled. This control is also reflected by differences in trace elemental and isotopic composition within (e.g. Hathorne et al., 2003; Kunioka et al., 2006) and between species (Blackmon and Todd, 1959; Lear et al., 2000). The sources of these biological variabilities are commonly termed the "vital effect" and need to be accounted for to improve the accuracy of reconstructions based on foraminiferal proxy-relationships (Erez, 2003). The response of foraminifera to ongoing ocean acidification provides an additional reason to analyze the sensitivity of their calcification pathway to changes in seawater alkalinity and $\mathrm{pH}$ since culture experiments have shown that shell weights of foraminifera decrease with decreasing seawater carbonate ion concentration (Bijma et al., 1999).

Foraminifera use seawater as the source to precipitate calcium carbonate from. Between uptake of seawater and calcite precipitation, the isotopic and trace elemental composition of the calcifying fluid is strongly modified (Erez, 2003). In particular, the original magnesium content of the seawater is heavily reduced by foraminifera, resulting in a low $\mathrm{Mg}$ content $\left(0.2-20 \mathrm{~mol} \% \mathrm{MgCO}_{3}\right)$ of most species' calcite (Blackmon and Todd, 1959; Bentov and Erez, 2006). It is therefore assumed that foraminifera have $\mathrm{Mg}^{2+}$ channels or -pumps that remove magnesium from vacuolized seawater. An internal pool with a very low $\mathrm{Mg} / \mathrm{Ca}$ ratio then remains and is used for calcite precipitation (Erez, 2003; Bentov and Erez, 2006). During calcification, the internal $\mathrm{pH}$ is increased to $\geq 9.0$ resulting in the conversion of bicarbonate into carbonate and thereby increases the calcite saturation state during chamber formation considerably (De Nooijer et al., 2009). The speed at which foraminifera can produce a new chamber suggests that all or most of the $\mathrm{Ca}^{2+}$ and inorganic carbon must be accumulated within the individual prior to chamber formation (Erez, 2003). This could be stored either in separate pools (Anderson and Faber, 1984; Ter Kuile

Published by Copernicus Publications on behalf of the European Geosciences Union. 
et al., 1989), as crystalline $\mathrm{CaCO}_{3}$ (as in miliolids: Hemleben et al., 1986; Debenay et al., 1996) or as amorphous $\mathrm{CaCO}_{3}$ (as suggested by Erez, 2003; Bentov and Erez, 2006).

To understand trace elemental/isotopic fractionation in foraminiferal calcite, a number of conceptual models of the calcification pathways have been developed that are based on experimental results and a suite of assumptions (Grossman, 1987; Ter Kuile et al., 1989; Ter Kuile and Erez, 1991; Elderfield et al., 1996; Erez, 2003). The ecological and physiological diversity among foraminiferal taxa spans symbiosis with and without photosynthetic organisms, benthic and planktic lifemodes, and precipitation of both calcitic and aragonitic test. This renders it very unlikely that the biomineralization process in foraminifera is similar among the taxa, which is well reflected in the substantial variety of $\mathrm{Mg}$ concentrations observed among foraminiferal $\mathrm{CaCO}_{3}$ (Bentov and Erez, 2006). Therefore, understanding biomineralization in foraminifera starts by obtaining all information on the calcification pathway from a single species, since it is not known to what extent observations from different species on e.g. seawater vacuolization can be generalized.

To put in perspective a number of recently obtained partition coefficients (particularly for $\mathrm{Mg}$ ) for the benthic foraminifer Ammonia tepida and environmental controls on their fractionations (De Nooijer et al., 2007; Dissard et al., 2009a, b, c; Raitzsch et al., 2009) we chose to analyze various parts of their calcification pathway by using fluorescent probes and Confocal Laser Scanning Microscopy (CLSM). The obtained results are used to construct a basic model and calculate calcium and carbonate budgets for calcification in A. tepida.

\section{Methods}

\subsection{Collection and maintainance}

Sediment containing foraminifera was collected at the intertidal flats near Dorum, Northwestern Germany in fall 2008. Upon return in the laboratory, material was sieved over a 1 $\mathrm{mm}$-screen to remove the largest macrofauna. The remaining sediment was stored at $10^{\circ} \mathrm{C}$ and used to isolate living foraminifera. Before isolation, a small amount of sediment was sieved over a $250 \mu \mathrm{m}$-mesh and the remaining material was screened for individuals of Ammonia tepida containing bright yellow protoplasm. Isolated, living adults of A. tepida were incubated at $25^{\circ} \mathrm{C}$ in $3 \mathrm{ml}$ of filtered seawater $(0.2 \mu \mathrm{m})$ in petridishes with a glass bottom and were fed living Dunaliella salina. Every two days the medium was replaced and once a week new food was provided. Approximately $5 \%$ of the adults underwent asexual reproduction within a week, resulting in 50-200 juveniles consisting of a megalospheric proloculus (diameter $\geq 40 \mu \mathrm{m}$ ). During the first week, these juveniles can build a new chamber every day and were therefore selected to be incubated with specific fluorescent probes and latex beads. The scanned juveniles consisted of 3-5 chambers and were approximately $100 \mu \mathrm{m}$ in diameter.

\subsection{Fluorescent probes}

To follow cell membrane cycling, individuals with 35 chambers were incubated for $15 \mathrm{~min}$ with the fluorescent probe FM1-43 (Invitrogen, Molecular Probes), dissolved in dimethyl sulfoxide (DMSO) and diluted with filtered seawater to a final concentration of $10 \mu \mathrm{M}$. The final concentration of DMSO in the seawater was $<5 \%$, which is not considered to affect the physiology of Ammonia (Toyofuku et al., 2008). After incubation, individuals were washed several times with filtered seawater and immediately placed under a Leica TCS CLSM. This type of microscopy allows scanning of a sample by excitation with defined wavelengths and subsequent recording of emitted light. Many fluorescent probes have been developed to bind to specific compounds or ions so that scans of incubated cells thus depict the distribution of specific organelles or ions. Exictation of specimens incubated with FM1-43 was accomplished by a $\mathrm{Kr} / \mathrm{Ar}$ laser with the excitation wavelength tuned to $488 \mathrm{~nm}$ and subsequent emission wavelengths between 600 and $650 \mathrm{~nm}$ were recorded.

Similar juveniles were placed in seawater with dissolved latex beads (Invitrogen, Molecular Probes). Since these beads cannot cross cell membranes, their uptake is an indication for endocytosis. Localization of the beads afterwards allows analysis of the fate of the endocytosed sea water. The beads had a diameter of $0.5 \mu \mathrm{m}$, an excitation optimum of $575 \mathrm{~nm}$ and an emission optimum of $610 \mathrm{~nm}$. Individuals were allowed to take up the beads for $24 \mathrm{~h}$, washed with seawater and scanned under the CLSM after excitation at $568 \mathrm{~nm}$.

Individuals of A. tepida were also incubated with $1 \mathrm{mg} / \mathrm{ml}$ fluorescein isothiocyanate-dextran with an average molecular weight of 10000 (FITC-D; Sigma-Aldrich) dissolved in seawater. The uptake of this fluorescent indicator allows visualization of vacuolization of seawater by foraminifera (Erez, 2003). In contrast to the uptake of the fluorescent beads, the uptake of FITC-D is indicative for fluid-phase endocytosis. A group of ten individuals was incubated for $1 \mathrm{~h}$ with FITC-D. These individuals were rinsed several times and placed under the CLSM and excited at $488 \mathrm{~nm}$, while emitted wavelengths between 500 and $560 \mathrm{~nm}$ were recorded. The individuals were not placed back into the fluorescent medium, but scanned after 1,2 and $8 \mathrm{~h}$ to track the intracellular fate of the ingested FITC-D. Inbetween the scans, the specimens were kept in the dark to prevent bleaching of the FITC.

Finally, juveniles were incubated with the fluorescent $\mathrm{Ca}^{2+}$-indicator Fluo3-AM (8 $\mu$ M: Toyofuku et al., 2008) for $24 \mathrm{~h}$. To track the $\mathrm{Ca}^{2+}$ utilization during chamber formation, individuals that were starting to make a new chamber were washed several times and placed under the CLSM and 
excited by $488 \mathrm{~nm}$ every minute until chamber formation was finished.

\section{Results}

\subsection{Cell membranes-vacuolization}

After 15 min of incubation with FM1-43, only cell membranes of the pseudopodia and around the aperture are stained. In the following hours, fluorescence spreads throughout the individual, starting with membranes in the outer chambers. In a number of specimens, this reveals a quasi-circular organization of cell membranes in the final chamber (Fig. 1a-b). This structure consists of an outer and inner sphere, with a number of strands of membranes connecting them. The shape of the outer sphere sometimes resembles the form of the final chamber rather than a geometrical sphere. The spaces inbetween the membrane strands, as well as the space within the inner sphere appeared not to be filled with cytoplasm. This is consistent with the absence of bright yellow-colored cytoplasm in the final chamber that is characteristic for this species. Rather, the cytoplasm was confined to thin films bordered by labeled cell membranes. Occasionally, small vesicles (diameter app. $3 \mu \mathrm{m}$ ) are transported from the edge of the outer towards the inner sphere (Fig. 1c-f).

During chamber formation, fluorescence of membranes near the site of calcification shows that pseudopodia extend radially from the former aperture towards the new chamber wall. Around this new wall, these pseudopodia converge and form a zone of cytoplasm delining the site of calcification (Fig. 1g).

\subsection{Fluorescent beads}

In the hours preceding chamber formation, foraminifera form a protective cyst around themselves, in which many latex beads in the individual's vicinity are incorporated (Fig. 2). A number of beads, however, are ingested prior to cyst formation and circulate through all chambers of the specimen. During calcification, some of these beads are transported from the cytoplasm into the final chamber towards the new chamber wall (Fig. 2).

\subsection{Fluid-phase endocytosis}

After one hour of incubation with FITC-D, fluorescence of this indicator was confined to the final chambers of the foraminifers. In most specimens the F-1 chamber was filled with FITC-D, while in some the fluorescence extended to the F-2 chamber as well (Fig. 3). In the hours following, the fluorescence disappeared from the chambers and the fluorescent intensity of the surrounding medium slightly increased.
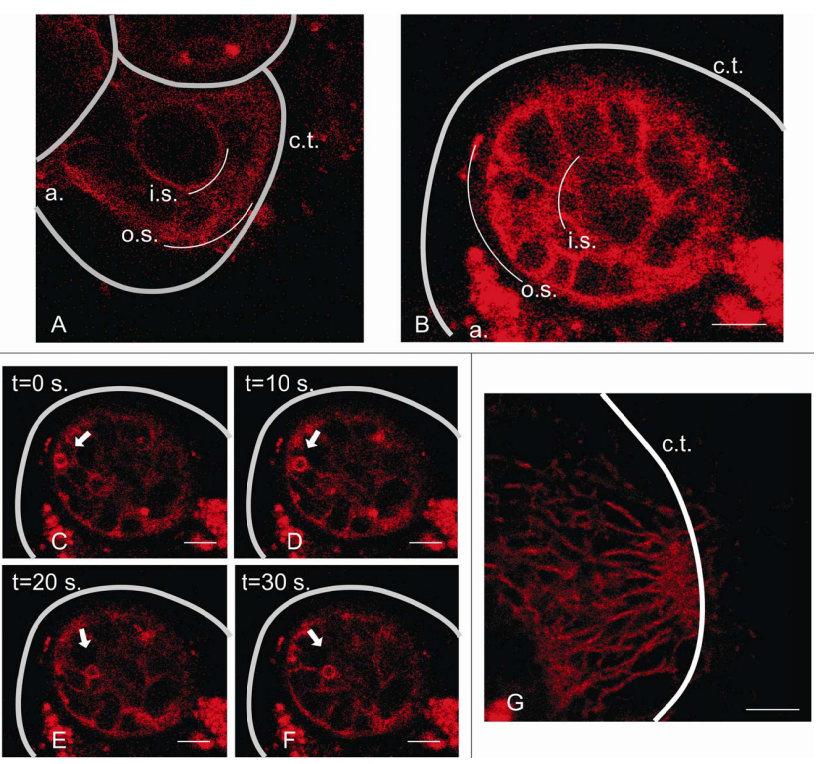

Fig. 1. Distribution of cell membranes in the final chamber of two juveniles of Ammonia tepida. (A) Location of the two spheres with a number of cytoplasmic strands inbetween them. (B) Another individual with a similar organization of these spheres. (C-F) Same individual as in (B), scanned every $10 \mathrm{~s}$. A small vesicle (arrows) is transported from the outer towards the inner sphere after which the vesicle dissapears. (G) Pseudopodial distribution in a third individual during chamber formation. The black arrow indicates the direction in which the aperture is situated. For all figures, the outline of the test of the final chamber is drawn to facilitate recognition of the position of the cell membranes and the calcite. a.=aperture, c.t.=calcitic test, i.s.=inner sphere, o.s.=outer sphere. Scale bars $=8 \mu \mathrm{m}$.

\section{4 $\mathrm{Ca}^{2+}$ during chamber formation}

Before and during chamber formation in juveniles of $\mathrm{Am}$ monia tepida, two types of fluorescence by Fluo3-AM are present. As reported before (Toyofuku et al., 2008), a weak background fluorescence exists throughout the cytoplasm, and in a number of chambers brightly fluorescent vesicles circulate through the cytoplasm. From the start until the end of chamber formation, a number of these bright vesicles are transported towards the site of calcification (Fig. 4). Commonly, these vesicles cross one chamber in less than a minute and with a time-lapse resolution of $1 \mathrm{~min}$, individual vesicles can therefore be tracked during this process. Although difficult to determine precisely, approximately $90 \%$ of the $\mathrm{Ca}^{2+}$ containing vesicles do not participate in chamber formation and remain in the cytoplasm after the new chamber is completed. In several individuals that were observed, the amount of such vesicles that are transported to the site of calcification in a new chamber did not exceed 20. 

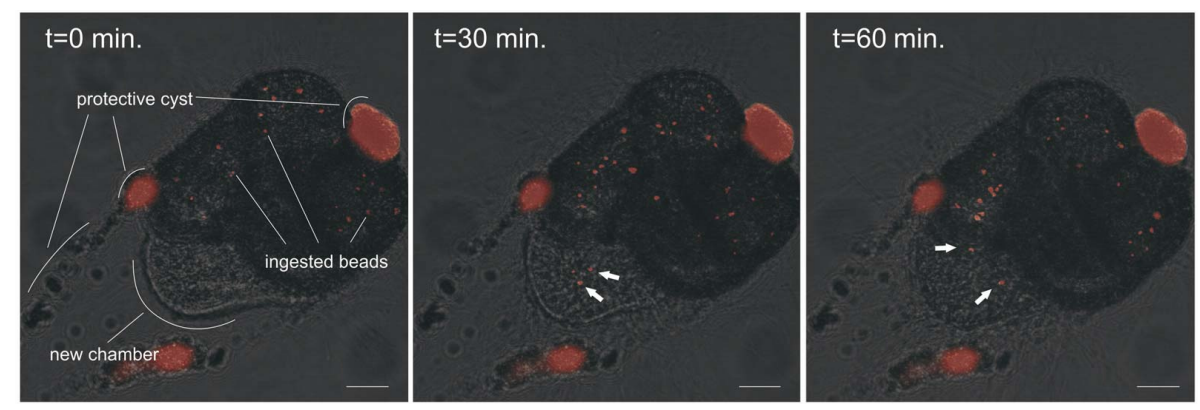

Fig. 2. Distribution of fluorescent beads in a calcifying juvenile of Ammonia tepida. Many beads are clustered and incorporated in the protective cyst that an individual forms prior to chamber formation and result in fluorescencent clusters at the surface of the foraminiferal test. The ingested beads, however, cycle within and between all five chambers of this individual. A number of them are transported into the newly formed chamber (arrows). Scale bars $=8 \mu \mathrm{m}$.

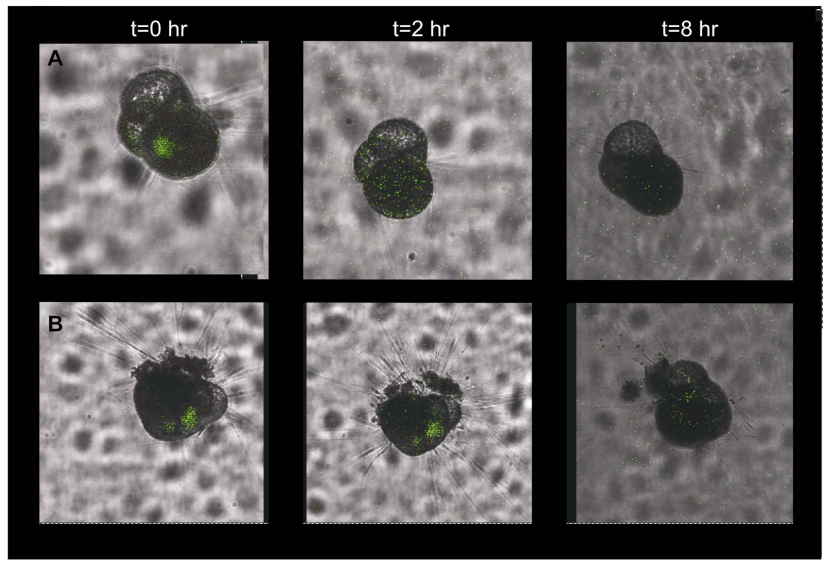

Fig. 3. Uptake of FITC-D by A. tepida. The ingested FITC-D resided in the $\mathrm{F}$ and $\mathrm{F}-1$ chambers after incubation in two specimens (A and B). The location of the FITC-D did not change notably, although the intensity decreased over time. At the same time, the fluorescence intensity of the surrounding medium increased.

\section{Discussion}

\subsection{Seawater vacuolization}

Theoretically, the internal $\mathrm{Ca}$ and carbonate pools from which foraminifera produce new chambers can be formed by transporting $\mathrm{Ca}$ ions and dissolved inorganic carbon via trans-membrane transport from the medium into the cytoplasm (as in coccolithophores; Brownlee and Taylor, 2004). It has been reported, however, that their internal pools are essentially modified seawater (e.g. Erez, 2003). Our results confirm that the common intertidal species Ammonia tepida is capable of both phagocytosis (Sect. 3.2) and fluid-phase endocytosis (Sect. 3.3). The distribution of cell membranes in the final chamber furthermore shows how endocytosis can take place in this species (Fig. 1). The reported fate of endocytosed seawater in other species (Erez, 2003; Bentov and
Erez, 2006), however, is not consistent with our observations. The endocytosed FITC-D (Fig. 3) disappears within hours after uptake, suggesting that seawater taken up in the final chambers is renewed rather than being processed intracellularly to form the fluids that foraminifera calcify from.

We propose therefore that in A. tepida, $\mathrm{Ca}^{2+}$ and inorganic carbon are extracted from endocytosed seawater and transported into separate, intracellular Ca- and DIC-pools. The seawater vacuoles, likely depleted in $\mathrm{Ca}^{2+}$, are then egested and new seawater is endocytosed. This would imply that for the A. tepida, the internal Ca- and DIC-pools may not resemble (modified) seawater (Elderfield and Erez, 1996), but a cellular fluid in which the ions for calcification are transported into.

\subsection{Ca-utilization during chamber formation}

The observation of calcium-rich vesicles during chamber formation (Fig. 4) was also reported by Toyofuku et al. (2008), but the time-lapse recordings reported here allow estimating the fluxes of intracellular $\mathrm{Ca}^{2+}$ in relation to chamber formation. To do so, we propose a conceptual model for Rotallid foraminiferal chamber formation (Fig. 5). In this simplification, a small individual consists of one spherical chamber and is building a second, small chamber with the shape of half a sphere. Whether the first, inner chamber is really one chamber or consists of a number of chambers (as the individuals in Figs. 2 and 3), does not affect the volume ratios between the new and older chambers significantly. For simplicity, we assumed that pore volume (reducing the volume of calcite in a new chamber) and the amount of calcite precipitated as a layer onto older chambers (increasing the volume of calcite precipitated; Erez, 2003) are in the same range and therefore do not need to be corrected for. We also assume that all $\mathrm{Ca}^{2+}$ for this new chamber is located in an intracellular $\mathrm{Ca}$ pool formed as described above: brought to the site of calcification either in the form of amorphous calcicium carbonate or as free Ca. In our simplified model, the new chamber has 

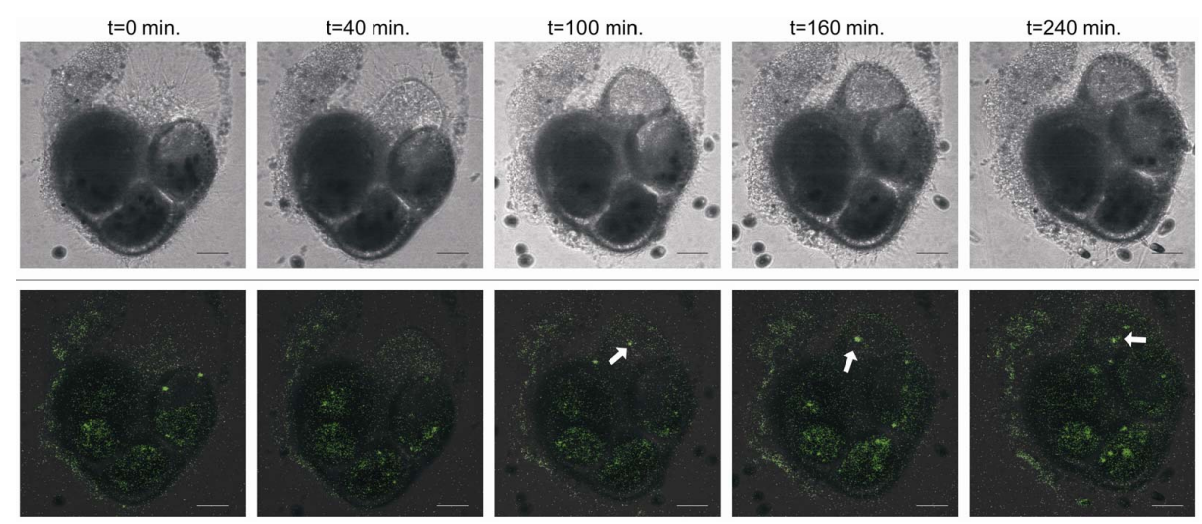

Fig. 4. Distribution of $\mathrm{Ca}^{2+}$ in a calcifying juvenile of Ammonia tepida. The upper row shows the extending pseudopodia at the onset of chamber formation $(t=0)$, the production of the primary organic sheet $(t=40 \mathrm{~min})$ and calcification onto this sheet $(t=100-240 \mathrm{~min})$. In the bottom row of figures, the confocal scans are superimposed on the pictures of the upper row. Arrows indicate $\mathrm{Ca}^{2+}-$ containing vesicles that are transported to the site of calcification. Scale bars $=20 \mu \mathrm{m}$.

a wall thickness of $3 \mu \mathrm{m}$, as estimated from embedded and cross-sectioned specimens (results not shown here).

The volume of the calcite precipitated to form this new chamber equals $1.33 \times 10^{-8} \mathrm{~cm}^{3} \mathrm{CaCO}_{3}$. With a density of $2.71 \mathrm{~g}$ per $\mathrm{cm}^{3}$, this new chamber contains $3.60 \times 10^{-8} \mathrm{~g}$ of $\mathrm{CaCO}_{3}$. With $40 \mathrm{wt} \% \mathrm{Ca}$, this means that $1.44 \times 10^{-8} \mathrm{~g}$ (or $3.6 \times 10^{-10} \mathrm{~mol}$ ) of $\mathrm{Ca}^{2+}$ must be inside the foraminifer at the onset of chamber formation. Assuming that all calcium is ultimately derived from seawater and that $100 \%$ of the calcium taken up is utilized for calcification, a volume of $3.50 \times 10^{-8} 1$ of seawater $\left(\left[\mathrm{Ca}^{2+}\right]=10.3 \mathrm{mmol} / \mathrm{l}\right)$ is needed.

In our simplified model, the individual has a total volume of $5.24 \times 10^{-10} 1$ (Fig. 5), excluding the volume of the new chamber. This means that this foraminifer has to process a volume of seawater that is app. 75 times its own volume to build up the entire internal Ca pool. Assuming that an individual could use $100 \%$ of its cytoplasm to store Ca vesicles, this Ca pool should have an average $\mathrm{Ca}$ concentration of $0.6 \mathrm{M}$. In a previous study the intracellular Ca pool of $A$. lobifera was estimated to contain $\mathrm{Ca}^{2+}$ with a concentration of 2-20 M (Erez, 2003). Considering the uncertainties in the methods and assumptions used, our results can be regarded as complementing the previous estimations. The Ca concentration of the putative pool cannot represent free $\mathrm{Ca}$ ions, because Ca-ATPases are not able to build up the respective $\mathrm{Ca}$ gradient between cytosol and vesicle-interior (for a more detailed discussion see: Langer et al., 2006, 2009). If we would assume that the $\mathrm{Ca}$ pool is basically seawater, i.e. $\mathrm{Ca}$ in an aqueous solution, the consequence is that the $\mathrm{Ca}$ pool does not contain enough $\mathrm{Ca}$ ions to produce a new chamber, implying that more Ca must be taken up during chamber formation. We have observed, however, that on average only 20 vesicles (with a diameter of $5 \mu \mathrm{m}$ ) were consumed in the production of a new chamber. Supposing that all $\mathrm{Ca}^{2+}$ necessary for the new chamber is stored in these 20 vesicles, its concentration would equal approximately $50000 \mathrm{M}$.

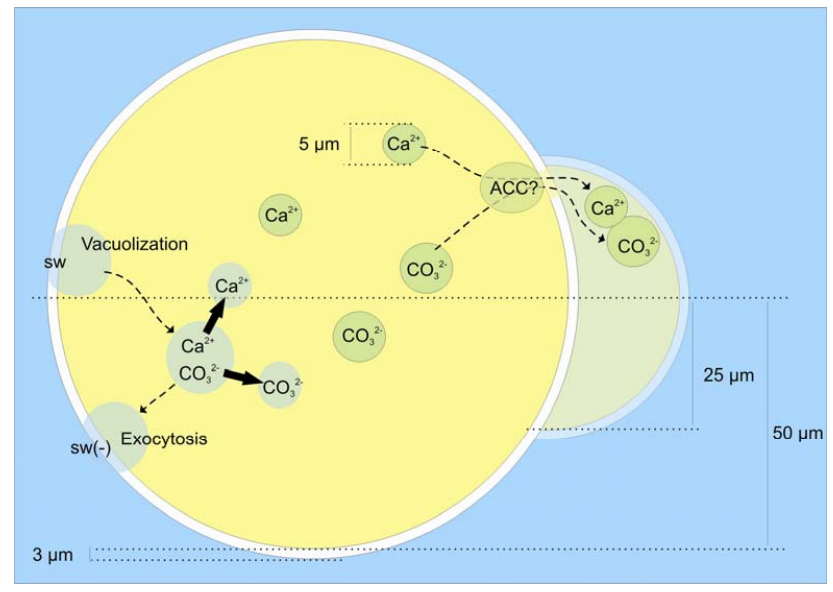

Fig. 5. Simplified representation of calcification in a Rotallid juvenile, based on our observations of chamber formation in Ammonia tepida. See text for detailed description of the processes. $\mathrm{ACC}=$ amorphous calcium carbonate, $\mathrm{sw}=$ seawater, sw $(-)=$ seawater depleted in $\mathrm{Ca}^{2+}$.

This estimation clearly shows that Ca cannot be transported to the site of calcification in vesicles containing seawater (i.e. $\sim 10 \mathrm{mMCa}$ ).

This conclusion only holds if most of the Ca used for a new chamber can be detected by our method. For example, it could be that most of the Ca-transport is through very small vesicles that bud off from the larger ones, but are invisible even when using confocal microscopy. Another possibility is that $\mathrm{Ca}$ is sequestered by specialized organic compounds in the Ca-pool that would lower the free calcium-concentration. Release, however, from these organics at the site of calcification should then be visible as a fluorescent zone at the new chamber wall, which was not observed. It may also be that most calcium is stored in the form of amorphous 
calcium carbonate (ACC) prior to chamber formation. The $\mathrm{Ca}$ in amorphous $\mathrm{CaCO}_{3}$ would not bind to Fluo3 and thus not cause fluorescence to be emitted from the Ca-containing vesicles. Furthermore, the ACC would not be detectable by examining these individuals with cross-polarized light. The ACC-storage suggestion may fit with the recent discovery that stable prenucleation clusters can form in a supersaturated medium prior to calcium carbonate precipitation (Gebauer et al., 2008; Pouget et al., 2009). Contrary to the classical theory, loose $\mathrm{Ca}$ - and carbonate ions may not directly participate in crystal growth, but rather calcite and aragonite grow by the addition of stable clusters of ACC. Foraminifera may be able to control these conversions precisely so that very little free calcium is observed to participate in chamber formation. In addition, the size of these ACC clusters may explain the observation that most foraminifera's tests consist of small crystallites (Debenay et al., 1996).

Acknowledgements. This research was sponsored through the European Project on Ocean Acidification (EPOCA) and the program on Biological Impacts of Ocean Acidification (BIOACID). G. L. acknowledges financial support by the Spanish Ministry of Education (Juan de la Cierva programme) cofunded by the European Social Fund and Ministry of Science and Innovation. We thank D. Abele for assistence on the methods used.

Edited by: J. Toporski

\section{References}

Anderson, O. R. and Faber Jr., W. W.: An estimation of calcium carbonate deposition rate in a planktonic foraminifer Globigerinoides sacculifer using ${ }^{45} \mathrm{Ca}$ as a tracer: A recommended procedure for improved accuracy, J. Foramin. Res., 14(4), 303-308, 1984.

Bentov, S. and Erez, J.: Impact of biomineralization processes on the $\mathrm{Mg}$ content of foraminiferal shells: a biological perspective, Geochem. Geophy. Geosy., 7(1), Q01P08, doi:10.1029/2005GC001015, 2006.

Bijma., J., Spero, H. J., and Lea, D. W.: Reassessing foraminiferal stable isotope geochemistry: Impact of the oceanic carbonate system (experimental results), in: Use of proxies in paleoceanography, edited by: Fischer, H. and Wefer, G., Springer, Berlin, Germany, 489-512, 1999.

Blackmon, P. D. and Todd. R.: Mineralogy of some foraminifera as related to their classification and ecology, J. Paleontol., 33(1), $1-15,1959$.

Brownlee, C. and Taylor, A. R.: Calcification in coccolithophores: A cellular perspective, in: Coccolithophores-from molecular processes to global impact, edited by: Thierstein, H. R. and Young, J. R., Springer, Germany, 31-49, 2004.

Debenay, J.-P., Guillou, J.-J., and Lesourd, M.: Colloidal calcite in foraminiferal tests: Crystallization and texture of the test, J. Foramin. Res., 26(4), 277-288, 1996.

De Nooijer, L. J., Reichart, G. J., Dueñas-Bohórquez, A., Wolthers, M., Ernst, S. R., Mason, P. R. D., and van der Zwaan, G. J.: Copper incorporation in foraminiferal calcite: results from culturing experiments, Biogeosciences, 4, 493-504, 2007, http://www.biogeosciences.net/4/493/2007/.

De Nooijer, L. J., Toyofuku, T., and Kitazato, H.: Foraminifera promote calcification by elevating their intracellular $\mathrm{pH}, \mathrm{P}$ Natl. Acad. Sci. USA, 106(36), 15374-15378, 2009.

Dissard, D., Nehrke, G., Reichart, G. J., and Bijma, J.: Impact of seawater $p \mathrm{CO}_{2}$ changes on calcification and on $\mathrm{Mg} / \mathrm{Ca}$ and $\mathrm{Sr} / \mathrm{Ca}$ in benthic foraminifera calcite (Ammonia tepida): results from culturing experiments, Biogeosciences Discuss., 6, 3771-3802, 2009a, http://www.biogeosciences-discuss.net/6/3771/2009/.

Dissard, D., Nehrke, G., Reichart, G.-J., and Bijma, J.: The impact of salinity on the $\mathrm{Mg} / \mathrm{Ca}$ and $\mathrm{Sr} / \mathrm{Ca}$ in the benthic foraminifera Ammonia tepida: results from culturing experiments, Geochim. Cosmochim. Ac., doi:10.1016/j.gca.2009.10.040, in press, 2009b.

Dissard, D., Nehrke, G., Reichart, G.-J., Nouet, G. J., and Bijma, $\mathrm{J}$.: Effect of the fluorescent indicator calcein on $\mathrm{Mg}$ and $\mathrm{Sr}$ incorporation into foraminiferal calcite, Geochem. Geophy. Geosy. 10(1), Q11001, doi:10.1029/2009GC002417, 2009c.

Elderfield, H., Bertram, C. J., and Erez, J.: A biomineralization model for the incorporation of trace elements into foraminiferal calcium carbonate, Earth Planet. Sci. Lett., 142, 409-423, 1996.

Elderfield, H. and Ganssen, G.: Past temperature and $\delta^{18} \mathrm{O}$ of surface ocean waters inferred from foraminiferal $\mathrm{Mg} / \mathrm{Ca}$ ratios, $\mathrm{Na}$ ture, 405, 442-445, 2000.

Elderfield, H., Yu, J., Anand, P., Kiefer, T., and Nyland, B.: Calibrations for benthic foraminiferal $\mathrm{Mg} / \mathrm{Ca}$ paleothermometry and the carbonate ion hypothesis, Earth Planet. Sci. Lett., 250, 633-649, 2006.

Erez, J.: The source of ions for biomineralization in foraminifera and their implications for paleoceanographic proxies, in: Reviews in mineralogy and geochemistry, vol. 54, edited by: Dove, P. M., De Yoreo, J. J., and Weiner, S., Mineralogical Society of America, Geochemical Society, 115-149, 2003.

Gebauer, D., Völkel, A., and Cölfen, H.: Stable prenucleation calcium carbonate clusters, Science, 322, 1819-1822, 2008.

Grossman, E. L.: Stable isotopes in modern benthic foraminifera: a study of vital effect, J. Foramin. Res., 17(1), 48-61, 1987.

Hathorne, E. C., Alard, O., James, R. H., and Rogers, N. W.: Determination of intratest variability of trace elements in foraminifera by laser ablation inductively coupled mass spectrometry, Geochem. Geophy. Geosy., 4(12), 8408, doi:10.1029/2003GC000539, 2003.

Hemleben, C. H., Anderson, O. R., Berthold, W., and Spindler, M.: Calcification and chamber formation in Foraminifera- a brief overview, in: Biomineralization in lower plants and animals, edited by: Leadbeater, B. S. C. and Riding, R., Systematics Association Special Vol. 30. Clarendon, 237-249, 1986.

Kunioka, D., Shirai, K., Takahata, N., Sano, Y., Toyofuku, T., and Ujiie, Y.: Microdistribution of $\mathrm{Mg} / \mathrm{Ca}, \mathrm{Sr} / \mathrm{Ca}$, and $\mathrm{Ba} / \mathrm{Ca}$ ratios in Pulleniantina obliquilloculata test by using a NanoSIMS: Implication for the vital effect mechanism, Geochem. Geophy. Geosy., 7(12), Q12P20, doi:10.1029/2006GC001280, 2006.

Langer, G., Gussone, N., Nehrke, G., Riebesell, U., Eisenhauer, A., Kuhnert, H., Rost, B., Trimborn, S., and Thoms, S.: Coccolith strontium to calcium ratios in Emiliania huxleyi: The dependence on seawater strontium and calcium concentrations, Limnol. Oceanogr., 51(1), 310-320, 2006. 
Langer, G., Nehrke, G., Thoms, S., and Stoll, H.: Barium partitioning in coccoliths of Emiliania huxleyi, Geochim. Cosmochim. Ac., 73, 2899-2906, 2009.

Lear, C. H., Elderfield, H., and Wilson, P. A.: Cenozoic deep-sea temperatures and global ice volumes from $\mathrm{Mg} / \mathrm{Ca}$ ratios in benthic foraminiferal calcite, Science 287(2), 269-272, 2000.

Morse, J. W. and Bender, M. L.: Partition coefficients in calcite: Examination of factors influencing the validity of experimental results and their application to natural systems, Chem. Geol., 82, 265-277,1990.

Mucci, A.: Growth kinetics and composition of magnesian calcite overgrowths precipitated from seawater: Quantitative influence of orthophosphate ions, Geochim. Cosmochim. Ac., 50(10), 2255-2265, 1986.

Nürnberg, D., Bijma, J., and Hemleben, C.: Assessing the reliability of magnesium in foraminiferal calcite as a proxy for water mass temperatures, Geochim. Cosmochim. Ac., 60(5), 803-814, 1996.

Pouget, E. M., Bomans, P. H. H., Goos, J. A. C. M., Frederik, P. M., De With, G., and Sommerdijk, N. A. J. M.: The initial stages of template-controlled $\mathrm{CaCO}_{3}$ formation revealed by Cryo-TEM, Science, 323, 1455-1458, 2009.
Raitzsch, M., Dueñas-Bohórquez, A., Reichart, G.-J., De Nooijer, L. J., and Bickert, T.: The effect of calcite saturation state on $\mathrm{Mg} / \mathrm{Ca}$ in cultured benthic foraminifera Heterostegina sp. and Ammonia tepida, Biogeosciences, submitted, 2009.

Ter Kuile, B., Erez, J., and Padan, E.: Mechanisms for the uptake of inorganic carbon by two species of symbiont-bearing foraminifera, Mar. Biol., 103, 241-251, 1989.

Ter Kuile, B. H. and Erez, J.: Carbon budgets for two species of benthonic symbiont-bearing foraminifera, Biol. Bull., 180, 489495, 1991.

Toyofuku, T., De Nooijer, L. J., Yamamoto, H., and Kitazato, H.: Real-time visualization of calcium ion activity in shallow benthic foraminiferal cells using the fluorescent indicator Fluo-3 AM, Geochem. Geophy. Geosy., 9(5), Q05005, doi:10.1029/2007GC001772, 2008. 